\title{
A specific role for hippocampal mossy fiber's zinc in rapid storage of emotional memories
}

\author{
Johnatan Ceccom, ${ }^{1,2}$ Hélène Halley, ${ }^{1,2}$ Stéphanie Daumas, ${ }^{3,4,5}$ and \\ Jean Michel Lassalle ${ }^{1,2,6}$ \\ ${ }^{1}$ Université de Toulouse, UPS, Centre de Recherches sur la Cognition Animale, F-31062 Toulouse Cedex 9, France; ${ }^{2}$ CNR, Centre de \\ Recherches sur la Cognition Animale, F-31062 Toulouse Cedex 9, France; ${ }^{3}$ Sorbonne Universités, UPMC Université Paris 06, Institut de \\ Biologie Paris Seine, F-75005 Paris, France; ${ }^{4}$ INSERM, UMR-S 1130, Neurosciences Paris Seine, F-75005 Paris, France; ${ }^{5}$ CNRS, UMR \\ 8246, Neurosciences Paris Seine, F-75005 Paris, France
}

\begin{abstract}
We investigated the specific role of zinc present in large amounts in the synaptic vesicles of mossy fibers and coreleased with glutamate in the CA3 region. In previous studies, we have shown that blockade of zinc after release has no effect on the consolidation of spatial learning, while zinc is required for the consolidation of contextual fear conditioning. Although both are hippocampo-dependent processes, fear conditioning to the context implies a strong emotional burden. To verify the hypothesis that zinc could play a specific role in enabling sustainable memorization of a single event with a strong emotional component, we used a neuropharmacological approach combining a glutamate receptor antagonist with different zinc chelators. Results show that zinc is mandatory to allow the consolidation of one-shot memory, thus being the key element allowing the hippocampus submitted to a strong emotional charge to switch from the cognitive mode to a flashbulb memory mode. Individual differences in learning abilities have been known for a long time to be totally or partially compensated by distributed learning practice. Here we show that contextual fear conditioning impairments due to zinc blockade can be efficiently reduced by distributed learning practice.
\end{abstract}

Hippocampus (HPC) is a brain structure highly preserved during evolution. Although its involvement in the formation of spatial and contextual memory is now clearly demonstrated, many features of its inner functioning are still to be explored. For instance, it has been established for a long time that two different hippocampal-based learning tasks, such as spatial memory in the Barnes circular maze task and contextual fear memory, may use different forms of synaptic plasticity (Bach et al. 1995).

Among the different subregions of Ammon's horn, a very unique connection network confers to the CA3 area the properties of an autoassociative matrix particularly well suited for the integration of multimodal information received from the entorhinal cortex (Marr 1971; McNaughton and Morris 1987; Treves and Rolls 1992; Lisman 1999). As shown in Figure 1, three types of synapses with specific properties form the peculiar architecture of this region. The synapse between the mossy fibers (MF) and the proximal and basal parts of pyramidal cells (MF-CA3) provide the first input to the CA3 region. Synaptic vesicles contained in the presynaptic element of MF axons from the granule cells of the dentate gyrus contain glutamate (Glut), neuropeptides, zinc $\left(\mathrm{Zn}^{2+}\right)$, ATP/ Adenosine, and GABA (Blaabjerg and Zimmer 2007). $\mathrm{Zn}^{2+}$ and Glut are colocalized and coreleased by excitation of hippocampal MF (Takeda et al. 2009). The second input is formed by axons of the direct perforant path from layer III of the entorhinal cortex (temporoammonic pathway [TA]) that synapse on the distal part of the dendritic tree of pyramidal cells (TA-CA3) and release glutamate (Bramham et al. 1991). The third input corresponds to the afferent axons of associative recurrent collaterals (ARCs) originating from ipsilateral and contralateral CA3 pyramidal cells that synapse on the middle part of the dendritic tree of CA3 pyramidal

\footnotetext{
${ }^{6}$ Corresponding author

E-mail lassalle@cict.fr

Article is online at http://www.learnmem.org/cgi/doi/10.1101/Im.033472.113.
}

cells and also release glutamate. In this study, we assume that the storage of new patterns of information in the CA3 region depends on associative plasticity in ARCs that would result from combined inputs from TA-CA3 and MF-CA3. The functioning of these three synapses relies on glutamate. Glut binds on different receptors, either postsynaptic (AMPAR, NMDAR, kainate, mGluR5) (Kwon and Castillo 2008; Rebola et al. 2008) or presynaptic (kainate, VGCC, mGluR2) for CA3 pyramidal cells (Shigemoto et al. 1997; Nicoll and Schmitz 2005; Pinheiro and Mulle 2008). Also, Glut binds on mGluR7 of interneurons and can induce long-term depression (LTD) (Nicoll and Schmitz 2005).

In addition, $\mathrm{MF}-\mathrm{CA} 3$ synapses and ARCs are also sensitive to the effects of $\mathrm{Zn}^{2+}$, which is coreleased with Glut at the CA3 synapse (Vogt et al. 2000). Functioning of the postsynaptic element of ARCs can also be modulated by spillover effects of $\mathrm{Zn}^{2+}$ released by the mossy fibers (Ueno et al. 2002). In this context, $\mathrm{Zn}^{2+}$ diffuses in the stratum radiatum and therefore, by inhibiting GABAA and NMDA receptors, may serve as a heterosynaptic spatiotemporal mediator in imprinting the history of MF activity in contiguous hippocampal networks (Ueno et al. 2002; Li et al. 2003). CA3 has been shown to play a central role in the assembly of complex representations that occur in different spatial functions such as orientation, storage of a list of places, or place recognition, but it could also play an essential role in the encoding of episodic memories (O'Keefe and Dostrovsky 1971). For instance, Nakazawa et al. (2003) showed that CA3 NMDARs involved in synaptic plasticity play a pivotal role in rapid hippocampal encoding of novel information for fast learning of one-time experience. The rapid

(C) 2014 Ceccom et al. This article is distributed exclusively by Cold Spring Harbor Laboratory Press for the first 12 months after the full-issue publication date (see http://learnmem.cshlp.org/site/misc/terms.xhtml). After 12 months, it is available under a Creative Commons License (AttributionNonCommercial 4.0 International), as described at http://creativecommons. org/licenses/by-nc/4.0/. 


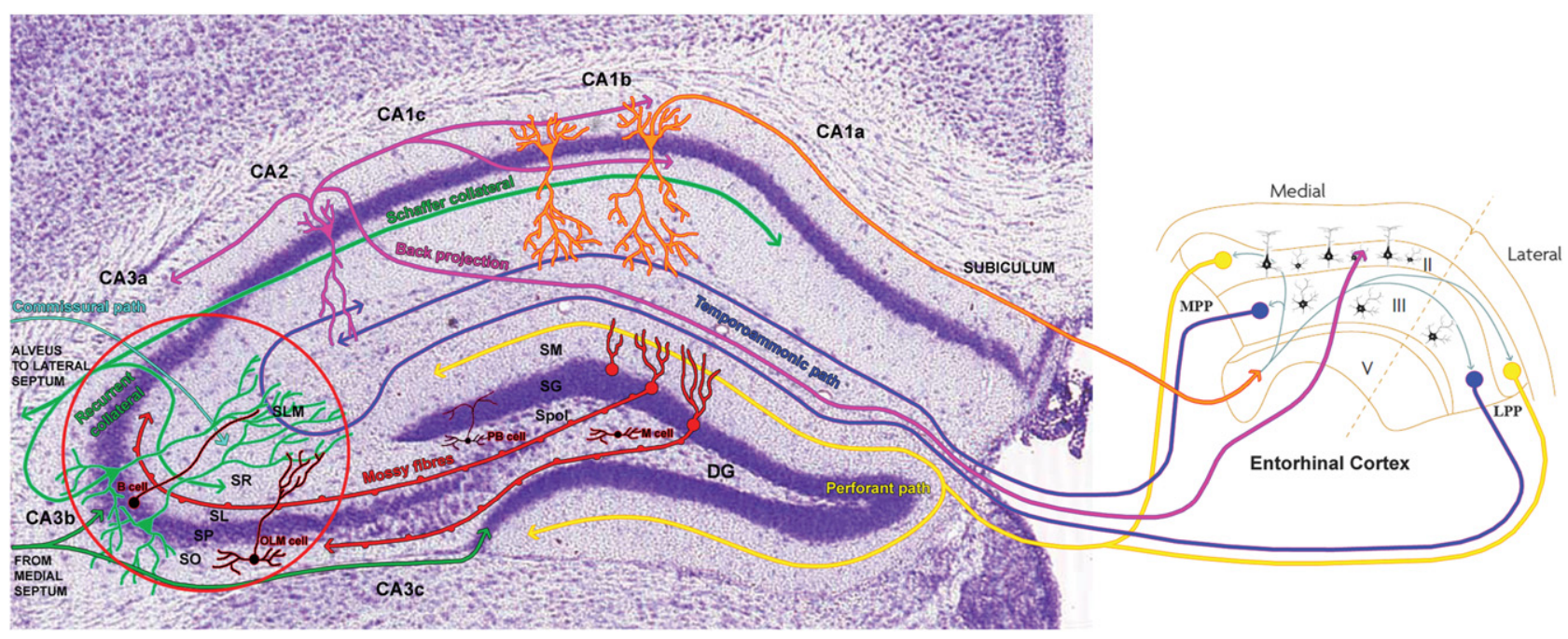

Figure 1. Connections network of the dorsal hippocampus and the CA3 area (circled). Hippocampal connections are drawn on the picture of a stained mouse section from Paxinos and Franklin (2001) (reprinted with permission from Elsevier (C) 2001). The axons of pyramidal cells in layer II of the entorhinal cortex (yellow) project to the dentate gyrus, those of stellate cells in layer III constitute the temporoammonic pathway (purple) to CA1, CA3, and CA2. Granule cells of the dentate gyrus send their axons (mossy fibers in red) to the pyramidal cells of the CA3 area. CA3 pyramidal cells axons divide into three collaterals (green): the recurrent collateral that synapses on apical dendrites of pyramidal cells in the stratum radiatum (SR), the Schaffer collateral that synapses on the proximal part of the apical dendrites of pyramidal cells in the CA2 and CA1 areas, and the third collateral that projects to the lateral septum via the alveus and the fimbria fornix (FF). CA3 pyramidal neurons also receive fibers from the contralateral hippocampus through the commissural path (blue-green). Projections from the medial septum reach CA3 and the DG (dark green). CA1 pyramidal neurons send their axons to layer $V$ of the entorhinal cortex via the subiculum. Retroconnections from layer V to layers III and II (light blue) complete the hippocampal formation circuit. Finally, CA2 pyramidal cell axons synapse on basal dendrites and on the proximal part of apical dendrites of CA1 pyramids while a collateral forms a monosynaptic backprojection to layer II of the medial entorhinal cortex, forming a novel "short-circuit" of the entorhinal hippocampal loop (pink). (B cell) Bi-stratified cell, (M cell) mossy cell, (OLM cell) oriens lacunosum moleculare cell, (PB cell) pyramidal basket cell, (LPP) lateral perforant path, (MPP) medial perforant path, (SG) stratum granulosum, (SL) stratum lucidum, (SM) stratum moleculare, (SLM) stratum lacunosum moleculare, (SO) stratum oriens, (SP) stratum pyramidale, (Spol) stratum polymorphe, (SR) stratum radiatum.

induction of long-term potentiation (LTP) is crucial for one-shot associative storage of sensory elements into CA3, without any need of repetitive pattern presentation (Bliss and Collingridge 1993). Therefore, mossy fibers could be crucially involved in rapid learning. Although long-term MF plasticity is known to result from a presynaptic NMDAR-independent mechanism, mediated by presynaptic kainite receptors (KAR) (Schmitz et al. 2001; Bortolotto et al. 2003), bursts of granule cell firing can also induce heterosynaptic potentiation in the TA-CA3 synapses (Ikegaya et al. 2003). Moreover, the existence of NMDA-dependent plasticity between MF and CA3 pyramidal cells which rely on NMDAR activation in the MF terminal zone has been established (Kerr and Jonas 2008; Kwon and Castillo 2008). This NMDAR-LTP could contribute to the property of conditional detonator of MF-CA3 synapses (Yeckel et al. 1999), which is supported by computational theories concerning the functioning of the autoassociative matrix of the CA3 region (Rolls 2007; see also Cerasti and Treves 2010, 2013). For a review of the various mechanisms of MF plasticity, refer to Nicoll and Schmitz (2005). A core issue of this study is to understand why there are large amounts of $\mathrm{Zn}^{2+}$ colocalized with glutamate at this synapse, though it is also found elsewhere, particularly in synaptic vesicles of the Schaffer collaterals (Sindreu et al. 2003), but in smaller quantities. As stated by Takeda et al. (2006), $45 \%$ of Schaffer collateral boutons are $\mathrm{Zn}^{2+}$ positive whereas all giant MF terminals in the CA3 region contain synaptic vesicles that stain for $\mathrm{Zn}^{2+}$. These authors hypothesized that $\mathrm{Zn}^{2+}$ released from Schaffer collaterals might suppressively modulate presynaptic and postsynaptic calcium signaling in the CA1, followed by the suppression of glutamate release. Using electrophysiological studies, they showed that low micromolar concentrations of $\mathrm{Zn}^{2+}$ potentiate CA1 LTP (Takeda et al. 2008a) and, more precisely, that they can differentially act on components of LTP at this synapse according to the strength of tetanic stimulation (Takeda et al. 2010). In the CA1 region of rat hippocampal slices, Izumi et al. (2006) observed that low micromolar concentrations of $\mathrm{Zn}^{2+}$ depressed NMDAR responses by $40 \%-50 \%$ and inhibited LTD but not LTP. Conversely, in CA3 low micromolar concentrations of $\mathrm{Zn}^{2+}$ attenuate MF LTP (Takeda et al. 2008b). Therefore, the main point of our study focused on understanding the particular advantage or functional specificity $\mathrm{Zn}^{2+}$ would give to the MF-CA3 synapse. Although the role of a neurotransmitter such as glutamate or even that of dynorphin (Daumas et al. 2007) is well known, that of $\mathrm{Zn}^{2+}$ is much more controversial (for recent reviews, see Sensi et al. 2009, 2011). $\mathrm{Zn}^{2+}$ divalent cations are massively present in synaptic buttons of mossy fibers. Vesicular $\mathrm{Zn}^{2+}$ is coreleased with glutamate depending on the activity of the presynaptic element, then quickly recaptured by transporter systems (Cole et al. 1999; Linkous et al. 2008) in order to reintegrate the presynaptic element and refill synaptic vesicles (Sudhof 1995). Once released into the synaptic cleft, $\mathrm{Zn}^{2+}$ may act on many pre- as well as postsynaptic targets. For instance, it can act as a neuromodulator through its action on GABA and glutamate release (Takeda et al. 2004). It is commonly accepted that its action is confined mainly to the allosteric modulation of ionotropic glutamate receptors (Ueno et al. 2002; Smart et al. 2004), but Malherbe et al. (2005) showed that $\mathrm{Zn}^{2+}$ may also act on metabotropic receptors. Finally, $\mathrm{Zn}^{2+}$ would also possess a specific receptor ( $\mathrm{nnR}$ ) at the MF-CA3 synapse (Besser et al. 2009). All of these targets represent a wide range of modulation of the MF-CA3 synapse by vesicular $\mathrm{Zn}^{2+}$, which gives it an extraordinarily complex role in the control of plasticity processes at this synapse. This cation has also been considered as an atypical neurotransmitter which could play a major role in potentiation of synaptic strength by translocating into the postsynaptic element (Li et al. 2001a; Gundelfinger 
et al. 2006) through the ionotropic glutamate receptors permeable to calcium (NMDA, AMPA, and KA-PC) and VDCC activated during synaptic transmission (Li et al. 2001b). This property emphasizes the joint action of glutamate and $\mathrm{Zn}^{2+}$ to the extent that $\mathrm{Zn}^{2+}$ can pass through the aforementioned receptors only if they are directly or indirectly (VDCC) activated by glutamate (Sensi et al. 2009). Once $\mathrm{Zn}^{2+}$ has penetrated into the postsynaptic element, it may interact with protein kinases and phosphatases involved in signaling pathways driving gene expression. Thus $\mathrm{Zn}^{2+}$, as a trans-synaptic factor, would be crucial to regulate the plasticity of the MF-CA3 synapse. $\mathrm{Zn}^{2+}$ may also act on intracellular $\mathrm{Ca}^{++}$concentration. The so-called "cross-talk" between $\mathrm{Zn}^{2+}$ and calcium suggests a competition between these two signaling ions (Takeda et al. 2007). At the postsynaptic element it has been shown that $\mathrm{Zn}^{2+}$ can affect a number of transduction pathways such as those involving PKC (Hubbard et al. 1991), CaMKII (Lengyel et al. 2000; Besser et al. 2009), MAPK (Park and Koh 1999; Besser et al. 2009), Erk 1 and 2 (Park and Koh 1999; Sindreu et al. 2011), or the Src family tyrosine kinases (Manzerra et al. 2001). The activation of Src is particularly interesting because the substrates of this kinase are involved in processes of synaptic plasticity. Indeed, the Src kinase activated by $\mathrm{Zn}^{2+}$ can phosphorylate the NMDA receptor and thus amplify its affinity for glutamate and enhance its excitability (Manzerra et al. 2001). Also, Huang et al. (2008) showed that $\mathrm{Zn}^{2+}$ can potentiate the MFCA3 synapse within minutes by transactivation of TrkB through increasing Src family kinase activity by an activity-regulated mechanism, independent of BDNF (see also Schildt et al. 2013). Finally, once entered in the cell, $\mathrm{Zn}^{2+}$ could participate virtually instantaneously to the assembly of proteins constitutive of the postsynaptic density (PSD), especially by binding to a specific motif of the Shank3 protein (Gundelfinger et al. 2006). Thus $\mathrm{Zn}^{2+}$ may modulate the structure and function of the PSD, allowing the expression of synaptic plasticity.

In previous studies from our group we analyzed the effects of CA3 mossy-fiber blockade on distributed spatial learning in the Morris water maze (MWM) by using $\mathrm{Zn}^{2+}$ chelators. We have shown that the injection, in the $\mathrm{CA} 3$ region, of diethyldithiocarbamate (DDC or DEDTC), a transmembrane chelator that chelates $\mathrm{Zn}^{2+}$ within synaptic vesicles, disrupted the acquisition of spatial learning with no effect on consolidation and recall. In contrast, the chelator calcium ethylenediamine tetraacetic acid (CaEDTA), which does not cross synaptic membranes and chelates selectively $\mathrm{Zn}^{2+}$ only after its release into the synaptic cleft, had no effect (Lassalle et al. 2000). However, Florian and Roullet (2004), using a massed procedure, showed that DEDTC also induced a disruption of consolidation in spatial learning whereas CaEDTA was still ineffective. It is therefore relevant to conclude that the disruptive effect of mossy-fiber blockade on spatial learning by DEDTC resulted actually from preventing glutamate release that normally occurs simultaneously with that of $\mathrm{Zn}^{2+}$, while $\mathrm{Zn}^{2+}$ itself had no specific role in this kind of learning, as demonstrated by the lack of effect of CaEDTA (Ceccom et al. 2013). Therefore glutamate, which is in all cases necessary to the acquisition of spatial learning, is also mandatory for its consolidation when acquisition is performed under a massed procedure. Unexpectedly, we demonstrated that both DEDTC and CaEDTA impaired the acquisition and consolidation of contextual fear conditioning (CFC), suggesting that in addition to glutamate, $\mathrm{Zn}^{2+}$ could also have a specific role in this kind of hippocampo-dependent task (Daumas et al. 2004). In a more recent study we confirmed that, whereas $\mathrm{Zn}^{2+}$ blockade by CaEDTA still does not impair memory consolidation of the platform location in the spatial navigation task when acquired under massed learning practice, CaEDTA prevents memory consolidation of onesession contextual fear conditioning (Ceccom et al. 2013). The key difference between these two types of hippocampo-dependent memories likely relates to the burden of emotional charge involved in CFC. According to Diamond et al. (2007), following a strong emotional learning experience, hippocampus and amygdala are both activated, the hippocampus rapidly shifting from a "configural/cognitive map" mode to a "flashbulb memory" mode. As a consequence, both structures afterward undergo a state in which the induction of new plasticity is suppressed, which facilitates the process of memory consolidation. It has been shown that the basolateral nucleus of the amygdala (BLA) and the basomedial nucleus of the amygdala (BMA) can modulate LTP at the perforant path-dentate granule cell synapses in association with perforantpath stimulation (Abe 2001; Abe et al. 2003; Nakao et al. 2004). Many studies showed that emotion enhances both hippocampal LTP and learning via norepinephrine regulation (Huang and Kandel 1996; Ikegaya et al. 1997; Nakazawa et al. 2003; Hu et al. 2007; Tully and Bolshakov 2010), confirming the obvious link between emotional feeling and integration degree of a unique spatiotemporal event.

We therefore analyzed the role of $\mathrm{Zn}^{2+}$ and that of glutamate receptors in a form of learning involving the memorization of an event with a strong emotional component and so likely to be acquired at once and to remain permanently associated with the context in which it occurred (Kuriyama et al. 2010), thus constituting episodic-like memory, a form of autobiographical declarative memory which is referred to as flashbulb memory. As in our previous studies, we chose fear conditioning, a form of Pavlovian conditioning that can be achieved in a single session (Phillips and LeDoux 1992; Daumas et al. 2007). The main feature of the CFC paradigm is to simultaneously implement two forms of Pavlovian conditioning: an association between a simple conditioned stimulus (CS), the tone and the US, which can be achieved only by involving the basolateral nucleus of the amygdala (BLA) (Sigurdsson et al. 2007) and a more complex form of conditioning, linking the US to the context in which it is issued. CFC can be achieved independently of the association sound-US provided that the mouse is allowed to explore the conditioning chamber for a sufficient time (at least 2 min) before shock delivery (Fanselow et al. 1990). The hippocampus is then involved, in addition to the BLA, to assemble in memory a representation of the context that will be later associated with US (Anagnostaras et al. 2001; Wiltgen et al. 2010) in one-shot memory.

Our main hypothesis is that MF $\mathrm{Zn}^{2+}$ and Glut could play complementary roles, especially during memory consolidation of CFC. To verify this assumption, we performed an in vivo pharmacological study in order to specify the role of $\mathrm{Zn}^{2+}$, along with that of ionotropic NMDA glutamate receptors of the three synapses likely to be involved in the consolidation of CFC acquired during a single session. As in our previous studies, we used the DEDTC and CaEDTA chelators along with ZnEDTA (zinc ethylenediamine tetraacetic acid) as a control chelator. Our results match those of Martel et al. (2010) and Sindreu et al. (2011) showing that mice lacking the ZnT3 transporter were actually impaired in contextual fear memory. In a second step we investigated the possible compensatory effects that could be generated by distributed learning practice on memory deficits induced by pharmacological blockade of Glut or/and $\mathrm{Zn}^{2+}$. In this case, varying the time period between two sessions of conditioning by observing a 2-h or a 24-h delay restored CFC memory abilities in treated mice. Altogether, this resulted in three companion experiments.

\section{Results}

\section{Overall view}

In order to investigate the involvement of $\mathrm{Zn}^{2+}$ and glutamate in contextual fear memory consolidation and the potential of 
remediation of spaced learning when this process is impaired, we compared mice performances following a 2-min, 2-h, or 24-h interval condition (IC) as presented in Figure 2A. Inactivation of zinc was enabled by the use of DEDTC $(200 \mathrm{mM})$ and CaEDTA $(200 \mathrm{mM})$ using as a control ZnEDTA $(200 \mathrm{mM})$. The concentrations of chelators were based on previous studies (Lassalle et al. 2000; Daumas et al. 2004). D-2-Amino-5-phosphonopentanoate (AP5) $(0.6 \mu \mathrm{g} / \mu \mathrm{L})$ was used to block glutamatergic transmission, following Fellini et al. (2009).

The expected actions of the various drugs used in this study and of their combinations result from the analysis of the literature presented in the introduction. They are developed below in the drugs section of the Materials and Methods.

In a first step, results of the three experiments were pooled for a global analysis (Fig. 2B). Afterward, analyses were performed by training interval condition. The homogeneity of freezing levels, around $80 \%$ in the three control groups across the three learning procedures, allowed direct comparisons between the three experiments. One-way analysis of variance (ANOVA) shows that the treatment factor had a significant contribution to the variation $\left(F_{(7,176)}=36.78, \quad P<0.001\right)$ as well as the condition factor $\left(F_{(2,176)}=105.95, P<0.001\right)$ and that both factors interacted significantly $\left(F_{(14,176)}=8.96, P<0.001\right)$. The ANOVA model explained $77.6 \%$ of the overall variance.

Three control groups were constituted to check for possible side effects linked to surgery and drug infusion: Sham mice underwent classical surgery for the implantation of guide cannulae but did not receive intracerebral injections of drug immediately after the fear-conditioning session. This first group of mice displayed

\section{A}
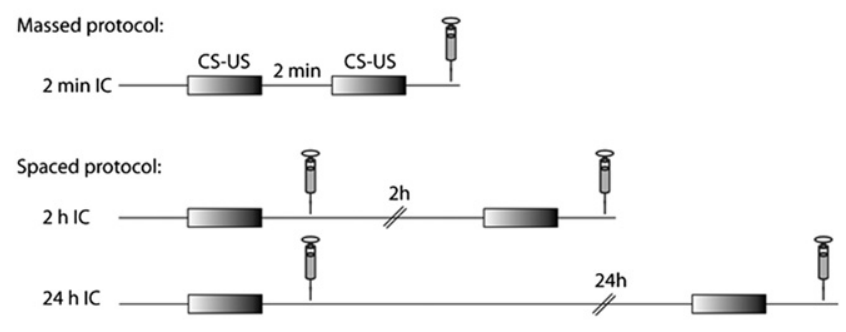

B

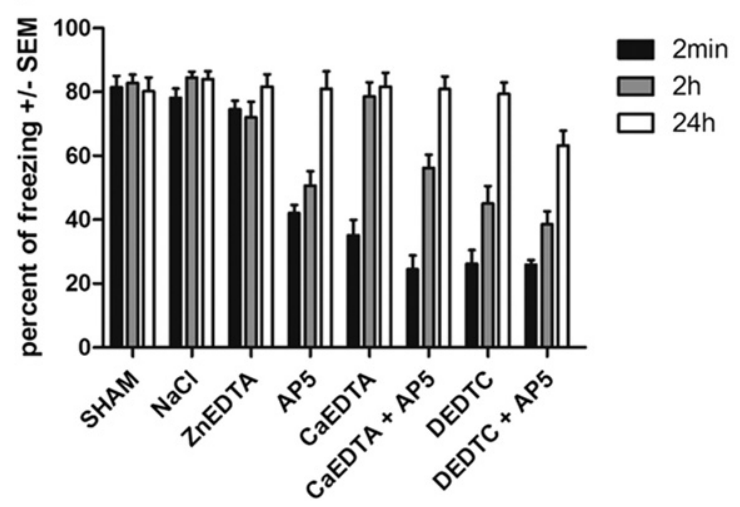

Figure 2. (A) Time course of the experiments under the three interval conditions studied. The 2-min IC is a massed learning condition, whereas the 2-h and 24-h IC allow learning to be acquired under distributed learning conditions. In all cases, the memory was assessed $24 \mathrm{~h}$ after the end of the last CS-US pairing. (B) Global analysis over the three conditions. Effects on freezing levels of five pharmacological treatments administered immediately after the conditioning trials and measured $24 \mathrm{~h}$ later, compared to three different controls. Results are presented as mean \pm SEM.

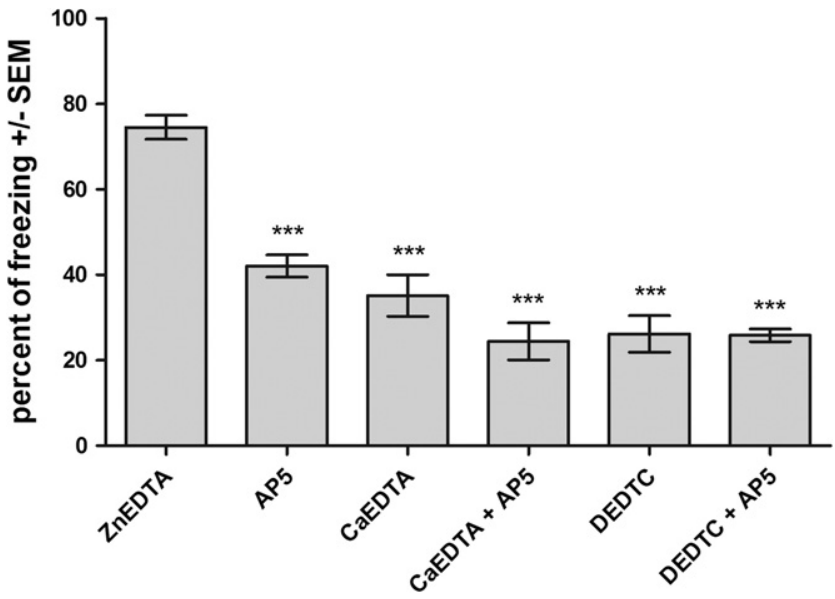

Figure 3. Contextual fear memory assay: 2-min interval condition. Effects on freezing levels of five pharmacological treatments administered immediately after the second conditioning trial of the massed learning session and measured $24 \mathrm{~h}$ later, compared to the ZnEDTA control. Results are presented as mean \pm SEM. $(* * *) P<0.001$.

a great percentage of freezing during the contextual fear memory assay $(81.48 \pm 2.00 \%)$, showing that the implantation of guide cannulae by surgery did not disturb either learning or memory of CFC. A second group of mice received bilateral infusions of $\mathrm{NaCl}$ in the CA3 hippocampal area immediately after the CFC session. Mice injected with $\mathrm{NaCl}$ displayed a great amount of freezing when submitted to the contextual fear memory assay $(82.11 \pm$ $1.50 \%)$ that did not differ from that of the sham group $(P=$ 0.451). These results show that infusion of a harmless solution like $\mathrm{NaCl}$ does not disturb learning and memory. This group can be considered as the best control for the AP5-injected group because this drug was dissolved in $\mathrm{NaCl}$. Finally, a third group of mice received ZnEDTA, which is the most appropriate control for $\mathrm{Zn}^{2+}$ chelators because it shows the highest similarity with chelator-treated groups. Indeed, ZnEDTA is a divalent ion chelator like CaEDTA and DEDTC but it is saturated with $\mathrm{Zn}^{2+}$. Mice injected with ZnEDTA displayed somewhat lower freezing scores (74.5 \pm $2.8 \%$ ) than sham and $\mathrm{NaCl}$ mice during the contextual fear recall test, although there was no significant variation $\left(F_{(2,22)}=1.414\right.$, $P=0.264$ ) among these three groups. In order to improve the power and efficiency of ANOVAs, we finally selected ZnEDTA-injected animals as a unique control group because it provides the most conservative control reference.

\section{Treatments effects under massed learning conditions}

\section{Experiment 1: 2-min interval condition}

A total of 55 mice received only one injection at the end of the CFC learning session in the 2-min interval condition (2-min IC). Freezing values for cue learning (not shown) ranged from $60.4 \%$ to $64.8 \%$, displaying no significant variance $\left(F_{(5,38)}=0.107\right.$, $P=0.990$ ). In contrast, as shown by Figure 3, injections of $\mathrm{Zn}^{2+}$ chelators and/or the NMDAR antagonist AP5 in the CA3 area of the dorsal hippocampus resulted in a significant overall variation of freezing to the context $\left(F_{(5,49)}=22.739, P<0.001\right)$. The proportion of the total variance explained by this model accounted for $69.88 \%$.

Post-hoc analyses showed that freezing levels in the different groups could vary significantly according to the drug they received. Mice injected with $\mathrm{Zn}^{2+}$ chelators and/or the NDMAR antagonist AP5 expressed significantly lower freezing than ZnEDTA 
mice $(P<0.001)$. The NMDAR antagonist AP5 caused significantly lower freezing than in the ZnEDTA control group $(P<0.001)$ during the contextual fear memory assay, suggesting that blockade of NMDARs by the antagonist AP5 induced a disruption of the consolidation process. The extracellular $\mathrm{Zn}^{2+}$ chelator CaEDTA induced reduced levels of freezing compared to the control group (ZnEDTA) $(P<0.001)$ but not to the AP5 group $(P=0.209)$. In the same way, mice injected with the intracellular $\mathrm{Zn}^{2+}$ chelator DEDTC displayed significantly lower freezing than the ZnEDTA control group $(P<0.001)$, the AP5 group $(P=0.002)$, and the CaEDTA group, although the difference was only marginally significant in this case $(P=0.081)$. Coinjection of CaEDTA and AP5 induced significantly lower freezing compared with that in the ZnEDTA control group $(P<0.001)$. Moreover, their freezing level was even lower than that of AP5 $(P=0.001)$ and CaEDTA-injected mice $(P=0.040)$. These results suggest cumulative effects of CaEDTA and AP5 when they are coinjected. DEDTC and AP5 were also coinjected in the same way. This group showed significantly lower freezing than the ZnEDTA control group $(P<0.001)$ and the AP5-injected group $(P=0.011)$, but did not differ significantly from CaEDTA- $(P=0.178)$, DEDTC$(P=0.745)$, or CaEDTA + AP5 -njected groups $(P=0.502)$.

To summarize, simultaneous blockade of postsynaptic NMDARs of MF-CA3, TA-CA3 and ARCs by AP5 dramatically disrupts the consolidation of fear conditioning to the context in 2-min IC. In addition, blockage of $\mathrm{Zn}^{2+}$ after being released into the MF-CA3 synaptic cleft by CaEDTA induces a disruption that is comparable to that of blocking NMDARs. When we combine the blocking of NMDARs at the three synapses and blocking of $\mathrm{Zn}^{2+}$ in the MF-CA3 synapse (CaEDTA + AP5) we obtain an even greater effect. In contrast, this effect does not differ from that resulting from the injection of DEDTC, that blocks the release of $\mathrm{Zn}^{2+}$ and Glut at MF-CA3 without affecting NMDARs at TACA3 and ARCs, which suggests that the latter are not sufficient to allow consolidation of CFC. Besides blocking the simultaneous release of $\mathrm{Zn}^{2+}$ and Glut at MF-CA3 with that of NMDARs at the three synapses by DEDTC + AP5, coinjection does not have a greater effect in the 2-min IC. We can therefore conclude that (1) the activation of the MF-CA3 synapse plays a crucial role in the consolidation of CFC in the 2-min IC and (2) the actions of $\mathrm{Zn}^{2+}$ and Glut at this synapse are essential and that these two mediators have complementary effects. We can consequently suggest that $\mathrm{Zn}^{2+}$ could act as a "booster" on memory consolidation of emotional learning achieved in one session, thus allowing the formation of a flashbulb memory. Total or partial experimental blockage of the release of these neurotransmitters or blockage of their receptors would allow simulating NMDARs or zincergic dysfunctions in the CA3 region, potentially resulting in disruption of the acquisition and/or memorization. Hence, when CA3 is prevented from operating as a detonator (by blocking $\mathrm{Zn}^{2+}$, once released, by CaEDTA) it will rather operate in cognitive mode and therefore a one-shot memory is no longer possible.

This raises the question whether hippocampal impairments obviously resulting from $\mathrm{Zn}^{2+}$ deficits definitely prevent emotional memories or can be, nonetheless, compensated in any way. Thus, it could be hypothesized that when CA3 can operate only in cognitive mode, splitting learning into different sessions could, nevertheless, allow learning achievement. Indeed, it has long been known that distributed practice, i.e., reviewing learning (Commins et al. 2003; Lehmann and McNamara 2011) or practicing a skill at spaced intervals (Overduin et al. 2006) is far more effective than massed practice in one heavy session. Thus, experimental data show that variations in learning abilities and memory between different strains of mice (Bovet et al. 1969), or in KO mice (Bourtchuladze et al. 1994) that fail to learn or memorize with massed learning trials, can be partially or totally over- come when trials are spaced in time. If that happens, the roles of Glut and NMDA receptors need to be clarified, assuming that in cognitive mode FM-CA3 LTP would be only presynaptic, whereas in detonator mode, $\mathrm{Zn}^{2+}$ would also activate the postsynaptic element through its action on NMDARs and/or through its translocation into the postsynaptic element as detailed above.

Therefore we wanted, in addition, to study whether the effects induced by these treatments on hippocampal deficits could be alleviated by a distributed learning procedure. We wondered if $\mathrm{Zn}^{2+}$ and Glut would be implicated in the same way if mice were submitted to spaced (distributed) trial learning. We tried to assess this hypothesis by using a modified protocol of fear conditioning. We designed two new experiments. In experiment 2 , conditioning sessions were spaced by a 2 -h interval (2-h IC), whereas in experiment 3 , the second trial was delayed by $24 \mathrm{~h}$ (24-h IC). In both cases, mice received the infusion of drugs immediately after each trial (see Fig. 2A).

\section{Treatments effects under distributed learning conditions}

\section{Experiment 2: 2-h interval condition}

A total of 48 mice were injected immediately after conditioning (Fig. 4). Injections of $\mathrm{Zn}^{2+}$ chelators and/or the NMDAR antagonist in the CA3 area of the dorsal hippocampus resulted in a significant overall variation of freezing $\left(F_{(5,42)}=11.384, P<0.001\right)$. The proportion of total variance explained by this model accounted for $57.54 \%$. As expected, freezing values for cue learning ranging from $60.4 \%$ to $71.6 \%$ (not shown) displayed no significant variance $\left(F_{(5,41)}=0.839, P=0.530\right)$. Post-hoc analyses showed that mice infused with the NMDAR antagonist AP5 showed again significantly lower freezing levels than the ZnEDTA control group $(P<0.002)$ during the contextual fear memory assay. On the other hand, this time the extracellular $\mathrm{Zn}^{2+}$ chelator CaEDTA had no significant effect on freezing levels (CaEDTA vs. ZnEDTA, $P<0.286$ ), whereas mice injected with the intracellular $\mathrm{Zn}^{2+}$ chelator DEDTC displayed significantly lower freezing than the ZnEDTA control group $(P<0.001)$ and the CaEDTA group $(P=0.001)$, while the DEDTC group did not differ significantly from the AP5 group $(P=0.397)$. Mice coinjected with CaEDTA + AP5 displayed significantly lower freezing than mice of the ZnEDTA control group $(P=0.016)$. Moreover, this coinjected group also showed

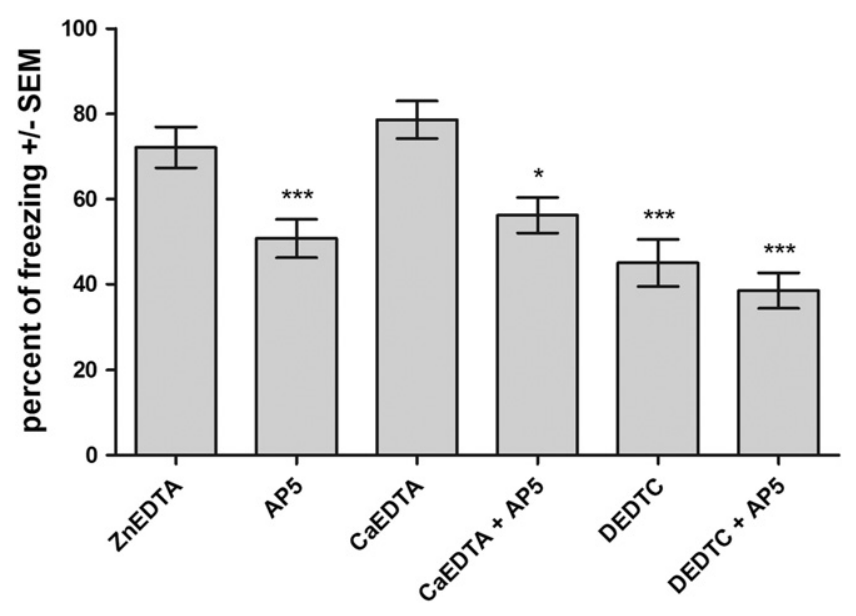

Figure 4. Contextual fear memory assay: 2-h interval condition. Effects on freezing levels of five pharmacological treatments administered immediately after each conditioning trial of the distributed learning session and measured $24 \mathrm{~h}$ later, compared to the ZnEDTA control. Results are presented as mean \pm SEM. $(*) P<0.05,\left({ }^{* * *}\right) P<0.001$. 
significantly lower freezing than the CaEDTA-injected group $(P<$ $0.001)$, whereas no significant differences appeared with the AP5 $(P=0.443)$ and DEDTC groups $(P=0.110)$. Coinjection of DEDTC and AP5 decreased freezing compared to the ZnEDTA control group $(P<0.001)$. However, this coinjected group showed a marginally significant lower level of freezing than the AP5 treated group $(P=0.085)$ and a significantly lower level of freezing than the CaEDTA + AP5 ( $P=0.015)$ group, whereas no significant difference appeared with the DEDTC group $(P=0.371)$.

To summarize, in the 2-h IC, $\mathrm{Zn}^{2+}$ was no longer necessary to the consolidation of CFC since CaEDTA had no effect on freezing level expressed during the contextual memory assay, whereas functional NMDARs were still required. On the other hand, and contrary to what could be observed in the 2-min IC, coinjection of DEDTC + AP5 resulted in a significantly greater impairment of CFC consolidation than coinjection of CaEDTA + AP5. This difference implies that blockade of Glut release by DEDTC at MFCA3 also prevents any action of Glut on presynaptic KARs while not blocking NMDARs at the other two synapses, as explained in the drugs section of Materials and Methods. If such an effect could be detected in the 2-h IC while it was not in 2-min IC, it is because the spacing between the two trials increased the memory strength of CFC in treated animals, whereas this phenomenon was masked by a floor effect in the 2-min IC.

\section{Experiment 3: 24- $h$ interval condition}

As can be seen from Figure 5, the injection of $\mathrm{Zn}^{2+}$ chelators and/ or the NMDAR antagonist AP5 in the CA3 area after each learning session to a total of 50 mice resulted in a low, albeit significant, overall variation of freezing $\left(F_{(5.44)}=3.657, P=0.007\right)$. The proportion of total variance explained by this model thus accounted for $29.36 \%$. Post-hoc analyses confirmed that only the DEDTC + AP5 group showed significantly impaired freezing when compared to the other groups $(P$ values ranged from $<0.008$ to 0.001). Then again, freezing values for cue learning (not shown) displayed no significant variance $\left(F_{(5,43)}=1.917, P=0.111\right)$. They ranged from $62.5 \%$ to $81.2 \%$, showing slightly higher values than in the 2-min IC and 2-h IC experimental conditions.

Therefore, a widely distributed training procedure allows impairments of CFC memory induced by various treatments to be fully restored, except for mice coinjected with DEDTC + AP5.

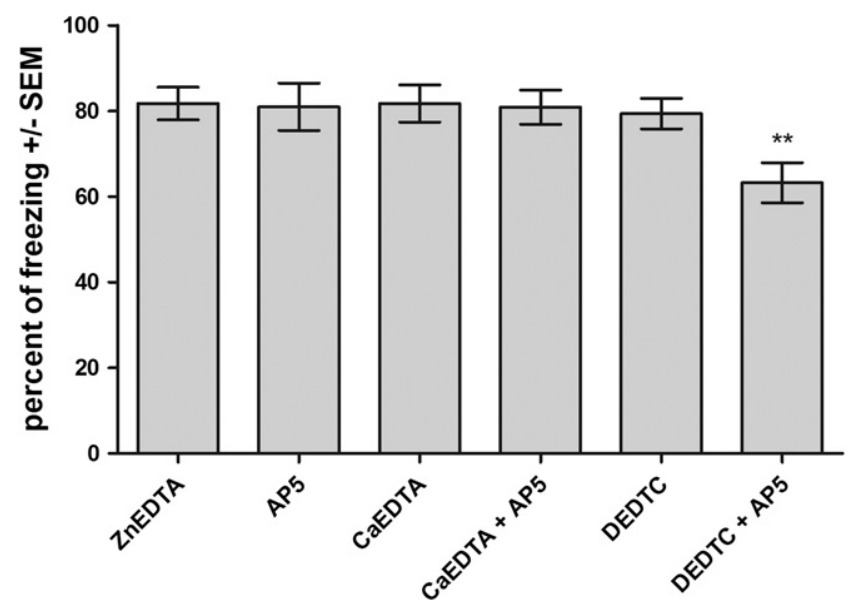

Figure 5. Contextual fear memory assay: 24-h interval condition. Effects on freezing levels of five pharmacological treatments administered immediately after each conditioning trial of the distributed learning session and measured $24 \mathrm{~h}$ later, compared to the ZnEDTA control. Results are presented as mean \pm SEM. $\left.{ }^{* *}\right) P<0.01$.
The result from this outcome is that functional impairments induced by $\mathrm{Zn}^{2+}$ chelators and NMDAR blockade can be rescued by the 24-h IC training procedure, except when the action of Glut on presynaptic KARs at the MF-CA3 synapse is also prevented, as explained in the Materials and Methods section.

\section{Discussion}

Selective blockades of the various CA3 synapses have overall deleterious effects on consolidation of HPC-dependent CFC. Conversely, as expected, they have no impact on consolidation of HPC-independent fear conditioning to the sound (data not shown).

An important outcome of this study is that the effects of treatment interact extensively with training procedures. The treatment $\mathrm{X}$ training condition interaction is both quantitative, since the effects of treatments are more pronounced in the 2-min IC than the 2-h IC and, a fortiori, the 24-h IC (the minimum rate of freezing induced by the most effective treatment [DEDTC + AP5] increases, respectively, from $26.8 \%$ to $38.5 \%$ and $62 \%$ when the IC delay shifts from $2 \mathrm{~min}$ to $2 \mathrm{~h}$ then $24 \mathrm{~h}$ ), and qualitative since treatment effects differ according to the training procedure (while all treatments have a significant effect in the 2-min IC, the effect of CaEDTA disappears in the 2-h IC and only the DEDTC + AP5 treatment still exerts a residual effect in the 24-h IC).

It is of paramount importance to point out that training conditions do not affect memory performances of control mice since sham, $\mathrm{NaCl}$, and ZnEDTA control groups display optimal capacities for acquiring and storing CFC whatever the training conditions. On the other hand, distributed training conditions allow fairly good levels of CFC achievement when CA3 functioning is disturbed by the treatments. Duration of the consolidation phase that separates the two acquisition trials is the main factor differentiating training conditions implemented in this study. Although the drug infusion regimen differed between experiment 1 and experiments 2 and 3, control mice receiving a second injection of saline did not show impaired freezing scores. Therefore, it is likely that different drug infusion regimens did not bias the results and that between groups variations are specific to drug effects.

The basic rationale for this study was that the 2-min IC procedure matches the conditions for one-shot memory with a very strong emotional component leading to the establishment of a flashbulb memory. In such a kind of rather extreme experience, all synapses in the CA3 autoassociative network are required since blockade of the action of Glut on postsynaptic NMDARs at MFCA3, CA3-PP, and ARCs by AP5 as well as blockade of $\mathrm{Zn}^{2+}$ at MF-CA3 synapses by CaEDTA impair CFC memory consolidation. Therefore $\mathrm{Zn}^{2+}$ and Glut must be both considered as necessary to flashbulb memory formation. Our conclusion is strengthened by the results of CaEDTA + AP5 coinjections that exert cumulative effects while each one is sufficient to partially disrupt CFC consolidation in the 2-min IC.

In contrast, previous work (Lassalle et al. 2000) showed that $\mathrm{Zn}^{2+}$ is not essential to the acquisition of spatial localization in the Morris water maze since CaEDTA did not impair learning, whereas the action of Glut at the MF presynaptic NMDARs and KARs would be still required, as shown by DEDTC injections. Such discrepancy between the involvement of $\mathrm{Zn}^{2+}$ in MWM and CFC arises because in the Morris water maze, the spatial component of learning (to be compared to the representation of context in the CFC) is acquired gradually over multiple trial sessions spaced $24 \mathrm{~h}$ apart. It requires an extended stay on the platform during which the gradual integration of bits of spatial information acquired during each trial and their progressive association with the positive reinforcement takes place. These are less stressful 
conditions than an unconditional negative reinforcement supplied by a violent shock. This argument still holds when spatial navigation learning is acquired under massed training practice (Ceccom et al. 2013).

On the other hand, during one-shot learning (2-min IC), as $\mathrm{Zn}^{2+}$ acts merely at mossy fibers synapses, it can be hypothesized that it allows them to shift from the "cognitive" to the "detonator" mode, which is critical for efficient consolidation of one-shot memory (Diamond et al. 2007). This would require both presynaptic and postsynaptic action of $\mathrm{Zn}^{2+}$ and glutamate since DEDTC and CaEDTA + AP5 induce similar disturbances. In CFC, such an operating mode could result from the activation of BLA (Ikegaya et al. 1997; Nakao et al. 2004; Diamond et al. 2007) which is able to drive hippocampal activity (Abe et al. 2003; Calandreau et al. 2006).

Moreover, in one-shot learning, the action of Glut on MF presynaptic KARs, likely responsible for the NMDAR independent presynaptic LTP, may not play a major role because the lack of stimulation of KARs resulting from the action of DEDTC + AP5, in addition to blocking of $\mathrm{Zn}^{2+}$ and Glut postsynaptic effects, exerts no additional disruptive effect on consolidation. However, such a presynaptic effect of Glut might be masked by a floor effect of the freezing level in the 2-min IC condition. In all experiments performed with massed learning condition, none of the treatments has lowered the freezing below $\sim 25 \%$. On the other hand, when the delay between trials or sessions is increased, the consolidation level is higher, even more so in the 24-h IC than in the 2-h IC. CaEDTA injections clearly show that $\mathrm{Zn}^{2+}$ is no longer necessary in either 2-h IC or 24-h IC. However, the postsynaptic action of Glut mainly at MF-CA3 synapses remains necessary to memory consolidation in the 2 -h IC which is no longer the case in the 24-h IC, as shown by AP5 and DEDTC injections.

Finally, even in distributed learning conditions (2-h IC and, a fortiori, 24-h IC), the presynaptic action of Glut at MF-CA3 remains necessary to the consolidation of pieces of learning acquired by mice whose NMDA receptors are blocked at the three synapses, since the additional blocking of the action of Glut receptors on the presynaptic MF-CA3 KARs induced by DEDTC + AP5 vs. CaEDTA + AP5 still induces a partial memory deficit.

Learning conditions with two trials distributed over $2 \mathrm{~h}$ or 24 $\mathrm{h}$ can therefore restore a normal level of acquisition and consolidation in mice whose activity of NMDARs at the MF-CA3, TACA3, and ARCs and the action of $\mathrm{Zn}^{2+}$ at MF-CA3 and ARC synapses are blocked, as long as the presynaptic action of Glut at MFCA3 is preserved. On the other hand, when all actors of the CA3 autoassociative matrix are blocked simultaneously by DEDTC + AP5, there still remains a possibility for a "meaningful" level of consolidation with distributed learning ( $40 \%$ of freezing in the worst case in 2-h IC and around 60\% in 24-h IC).

These observations suggest that in the absence of MF-CA3 function, other synapses that would not be directly implicated in driving CA3 recurrent network could partially overcome this disruption. On the other hand, it could also be considered that other hippocampal subregions, like CA2 or CA1, might partially compensate CA3 dysfunction in case of recurrent network impairment. As this is not likely because of the lack of experimental support, we rather suggest that the spacing effects observed in our experiments rely on a particular dynamic of protein synthesis machinery in the CA3 area during spaced training, as already suggested by Scharf et al. (2002). Also, Bourtchouladze et al. (1998) and Kogan et al. (1997) showed that a spaced learning procedure could induce multiple CREB activation (even of small intensity) that could imply multiple protein synthesis waves. In our experimental conditions, these small amounts of protein might be sufficient to partially or totally compensate for the disruption of CA3 area function.
When mice are reexposed to the apparatus after a large ITI (24-h IC), reconsolidation may occur, although it can only reactivate a defective memory from the first session whose consolidation was blocked by drugs. This process may, in turn, be blocked by the drugs, although the effects of chelators on reconsolidation are not actually known. Regarding NMDAR receptors, Lee et al. (2004) have shown that, although there is a common requirement for NMDAR activity in consolidation and reconsolidation, there are divergent neurobiological pathways of hippocampal contextual fear memory consolidation and reconsolidation at the level of intracellular cascades. Indeed, whereas BDNF expression is required for memory consolidation, Zif268 expression is necessary for reconsolidation. More recently, Lee and Hynds (2013) revealed that there are functional NMDAR-ERK-BDNF and NMDARIKKa-Zif268 pathways for consolidation and reconsolidation, respectively.

In summary, the present pattern of results reveals that $\mathrm{Zn}^{2+}$ released in the MF-CA3 pathway is the key element, in addition to Glut, to allow one-shot learning of contextual fear memory, although a $\mathrm{Zn}^{2+}$ deficiency might be compensated by distributed learning sessions based on various possible mechanisms according to ITI duration.

\section{Materials and Methods}

All experiments were performed in strict accordance with the policies of the European Union (86/609/EEC), the French National Committee of Ethics $(87 / 848)$, and the local committee's recommendations (C 31-555-11, Direction départementale de la protection des populations) for the care and use of laboratory animals. Animal surgery and experimentation are authorized by the French Direction of Veterinary Services to J.M.L. (\#31-122, 2007) and S.D. (\#75-1651).

\section{Animals}

Subjects were 9- to 12-wk old C57BL/6J male mice obtained from Charles River and reared in the CRCA breeding facility. They were housed in groups of 3-5 per cage and maintained at a constant temperature $\left(21 \pm 1^{\circ} \mathrm{C}\right)$ with a 12-h light/12-h dark cycle (lights on at 8:00 a.m.) Water and food were available ad libitum.

\section{Drugs}

All drugs were provided by Sigma Chemical Co. Various heavy metal chelators were used for their particular affinity with $\mathrm{Zn}^{2+}$ ions and their functional properties.

To assess the role of NMDARs in CFC, we used the D-2-amino-5-phosphonopentanoate (AP5) competitive antagonist of NMDA receptors. AP5 was applied alone or jointly with a $\mathrm{Zn}^{2+}$ chelator, immediately after learning. It acts at the three synapses of the hippocampal CA3 region (MF-CA3, TA-CA3, and ARCs). In contrast, AP5 does not prevent the binding of Glut on other receptors such as AMPA/kainate or mGluR. Thus NMDA-independent plasticity of MF-CA3 synapses, dependent on presynaptic kainite receptors (KARs), should not be affected by this treatment. It is therefore expected that postsynaptic LTP at TA-CA3 and ARC synapses is mostly disturbed. However, this does not exclude a deleterious effect of AP5 on MF postsynaptic LTP leading to a disruption of the metaplasticity of the MF-CA3 synapse. This treatment should allow evaluating the involvement of TA-CA3 and ARC synaptic plasticity in the consolidation of CFC acquired in a single session.

Sodium chloride $(\mathrm{NaCl})$ was used as a control for this antagonist.

CaEDTA (calcium ethylenediamine tetraacetic acid) is a $\mathrm{Ca}^{++}$-saturated chelator of divalent ions widely used as an extracellular zinc chelator (Koh et al. 1996; Li et al. 2001a,b). It has a particular affinity for $\mathrm{Zn}^{2+}\left(K_{\mathrm{d}}=10^{-16.4} \mathrm{M}\right)$ but its affinity for $\mathrm{Ca}^{2+}$ and $\mathrm{Mg}^{2+}$ is low enough not to alter the concentrations of 
these two cations. Its action kinetics is proportional to its concentration. Furthermore, this molecule cannot pass through membranes, making it an exclusively extracellular $\mathrm{Zn}^{2+}$ chelator that does not affect its intracellular homeostasis. This molecule was chosen to trap specifically free $\mathrm{Zn}^{2+}$ and $\mathrm{Zn}^{2+}$ resulting from the exocytosis of glutamate vesicles at the MF-CA3 synapse following the activity of granule cells of the dentate gyrus. The action of CaEDTA will thus be limited mainly to this synapse by preventing $\mathrm{Zn}^{2+}$ acting on its multiple targets. Specifically, CaEDTA will block the action of $\mathrm{Zn}^{2+}$ on glutamate receptors (NMDA, AMPA, KA) on VDCC, on TrkB, KATP, ZnR, and prevent its translocation into the postsynaptic element. The decrease of $\mathrm{Zn}^{2+}$ ergic activity should result mainly in a disruption of MF plasticity and possibly of ARCs that experience the spillover of $\mathrm{Zn}^{2+}$ from MF. In contrast, fast glutamatergic transmission and glutamate-related plasticity should be preserved which allows us to suggest that plasticity of TA-CA3 synapses and ARCs would not be disrupted by this treatment. Moreover, presynaptic and postsynaptic LTP of NMDA receptors in the MF-CA3 synapse should not be altered if the $\mathrm{Zn}^{2+}$ is not a critical modulator of both forms of plasticity. This treatment would allow evaluating the involvement of $\mathrm{Zn}^{2+}$ released into the CA3 region and especially in the MF-CA3 synapse during CFC consolidation.

DEDTC (diethyldithiocarbamate) is another chelator of divalent ions with high affinity for $\mathrm{Zn}^{2+}$ that has the particularity to cross membranes. Thus, this molecule has been successfully used in numerous in vitro and in vivo studies to trap intra- and extracellular $\mathrm{Zn}^{2+}$ (Frederickson et al. 1990; Takeda et al. 1999; Lassalle et al. 2000; Lu et al. 2000; Daumas et al. 2004). Moreover, its specific action at MFs suggests that it inhibits exocytosis of synaptic vesicles containing co-located $\mathrm{Zn}^{2+}$ and Glut, like DCGIV that inhibits the machinery of MF synaptic transmission (Daumas et al. 2009). The use of this drug would therefore hinder the action of $\mathrm{Zn}^{2+}$ and Glut on all their targets, whether pre- or postsynaptic, and specifically at the FM-CA3 synapse. DEDTC could theoretically disrupt presynaptic MF LTP by preventing the release of glutamate and thus its binding on KARs, but also the postsynaptic LTP of NMDA receptors, and thus suppress any excitatory influence on the FM-CA3 synapse. However, DEDTC would not affect LTP of TA-CA3 synapses or that of the ARCs. However, the chelation of $\mathrm{Zn}^{2+}$ at the MF-CA3 synapse preserves ARCs from modulatory influences resulting from the spillover of $\mathrm{Zn}^{2+}$ released by MF and could therefore modify the properties of LTP at this synapse. Were transmission and LTP at the MF-CA3 synapse to play a role in the consolidation of contextual learning achieved in a single session, then the effect of DEDTC should induce a dramatic decrease in behavioral performance of animals.

Coinjection of CaEDTA + AP5 will allow chelating extracellular $\mathrm{Zn}^{2+}$ released after exocytosis of MF glutamate vesicles but also inhibit the activity of NMDA receptors at the three synapses of the CA3 region. However, this treatment will not impede the action of Glut on the other receptors and particularly on the MF presynaptic KARs. Coinjection of both drugs is expected to disrupt LTP at TA-CA3 synapses and ARCs but also postsynaptic LTP of NMDA receptors at the MF-CA3 synapse. This treatment should allow assessing the involvement of postsynaptic LTP of the three CA3 synapses and measuring the role of MF presynaptic LTP in the consolidation of a flashbulb memory.

Coinjection of DEDTC + AP5 will disrupt the activity of the CA3 region at different levels. DEDTC will prevent the release of both $\mathrm{Zn}^{2+}$ and Glut from vesicles of the MF-CA3 synapse and thereby disrupt MF LTP at both the pre- and postsynaptic sides. Furthermore, the addition of AP5 will allow blocking the activity of NMDA receptors at the three synapses of the CA3 region. This treatment will therefore impede the overall effects of Glut and $\mathrm{Zn}^{2+}$ in the CA3 region and their possible synergistic effect on NMDA receptors. Thus the involvement of these different synapses in the consolidation of contextual learning should be evaluated and the possible role of other actors such as KAR or VDCC, whose activity is preserved at TA-CA3 and ARC synapses, revealed.

ZnEDTA (zinc ethylenediamine tetraacetic acid) is a chelator of divalent ions saturated with $\mathrm{Zn}^{2+}$. This molecule is used as a control for other chelators since its affinity for $\mathrm{Zn}^{2+}$ is such $\left(K_{\mathrm{d}}=10^{-15} \mathrm{M}\right)$ that it is unable to sequester other ions (Koh et al. 1996). Therefore, $\mathrm{Zn}^{2+}$ fastened on this drug will not be released to allow the capture of other cations, such as calcium or magnesium, that have much lower affinity $\left(K_{\mathrm{d}}=10^{-7.3} \mathrm{M}\right.$ and $K_{\mathrm{d}}=10^{-5.4} \mathrm{M}$, respectively).

All these drugs were solubilized in $\mathrm{NaCl}(0.9 \%)$ and stored at $-20^{\circ} \mathrm{C}$. The time window for DEDTC and CaEDTA had been estimated as $2 \mathrm{~h}$ (Stupien et al. 2003). The concentration of chelators was $200 \mathrm{mM}$ and $3.04 \mathrm{mM}$ for AP5.

\section{Implantation of guide cannulae for intrahippocampal microinfusions}

Mice were anesthetized with a mixture of ketamine hydrochloride (100 mg/kg, i.p.) (Vibrac) and xylazine (15 mg/kg, i.p.). Stainless-steel guide cannulae $(24 \mathrm{G}, 7 \mathrm{~mm})$ were implanted bilaterally in the cortex above the dorsal hippocampus using standard stereotaxic procedures. Cannulae coordinates for the CA3 infusion site were as follows: (AP) $-1.7 \mathrm{~mm}$ posterior to bregma, (ML) $\pm 2.5 \mathrm{~mm}$, (DV) $-1.5 \mathrm{~mm}$ from the skull, according to the brain atlas of Paxinos and Franklin (2001). Dental cement (polycarboxylate, Sigma) was used to fasten guide cannulae to the skull. Stainless-steel obturators were inserted in guide cannulae to prevent occlusion and left in place until the infusions were made. A total of 280 male mice underwent surgery and behavioral testing. After surgery, mice were allowed at least $1 \mathrm{wk}$ to recover. All experiments were carried out in the afternoon during the diurnal phase.

\section{Apparatus for behavioral testing}

Conditioning took place in a conditioning chamber that consisted of a cubic metal box $(27 \mathrm{~cm} \times 26.5 \mathrm{~cm} \times 27 \mathrm{~cm})$ with three black sides and a Plexiglas front wall, through which experimental subjects were videotaped. The floor was made of a grid with 22 stainless-steel rods (diameter $4 \mathrm{~mm}$ ) spaced $1 \mathrm{~cm}$ apart and connected to a generator (Panlab) delivering shocks of defined duration $(2 \mathrm{sec})$ and intensity $(0.7 \mathrm{~mA})$ through a shock-scrambler unit. The grid was placed on a high-precision scale to measure the variations of weight induced by the movements of the animal. This device allows an automatic detection of movements and consequently a detection of freezing behavior. The loudspeaker producing the tone $(1500 \mathrm{~Hz}, 85 \mathrm{db}, 30 \mathrm{sec})$ was fixed on the lid of the conditioning chamber. The experimental device, lit by a $60-\mathrm{W}$ white bulb, was surrounded by a white curtain. Two black and white patterns faced the conditioning chamber, providing distal cues, and two proximal patterns were attached to the internal walls of the chamber. Experiments were videotaped on line with a camera placed in front of the conditioning chamber and recorded on the computer acquisition system. Monitors were placed in the adjacent room where all the electronic system was settled. The conditioning chamber was cleaned with $70 \%$ aqueous ethanol before each conditioning session and before each contextual fear memory assay. Contextual memory level was measured in the same experimental conditions as conditioning, whereastonelearning was assessed in a modified context. For that purpose, the curtain and external patterns were removed. The modified chamber was made triangular by the adjunction of two walls and a floor partition made of uniform light-brown polycarbonate. This apparatus was washed with $1 \%$ acetic acid and lit by a $40-\mathrm{W}$ red bulb.

\section{Contextual fear conditioning procedure}

Behavioral testing started $1 \mathrm{wk}$ after surgery. In this study we used three types of conditioning procedures. The first, called " 2 -min interval condition" (2-min IC), is a classic version of contextual fear conditioning which consisted of a single conditioning session with two trials. During conditioning, each mouse was introduced into the conditioning chamber for a total of $5 \mathrm{~min} 30 \mathrm{sec}$. After a 2-min exploration period, a sound (CS) was emitted for $30 \mathrm{sec}$, and a foot-shock (US) was superposed to the tone during the last $2 \mathrm{sec}$. After an inter-trial interval of $2 \mathrm{~min}$, the 


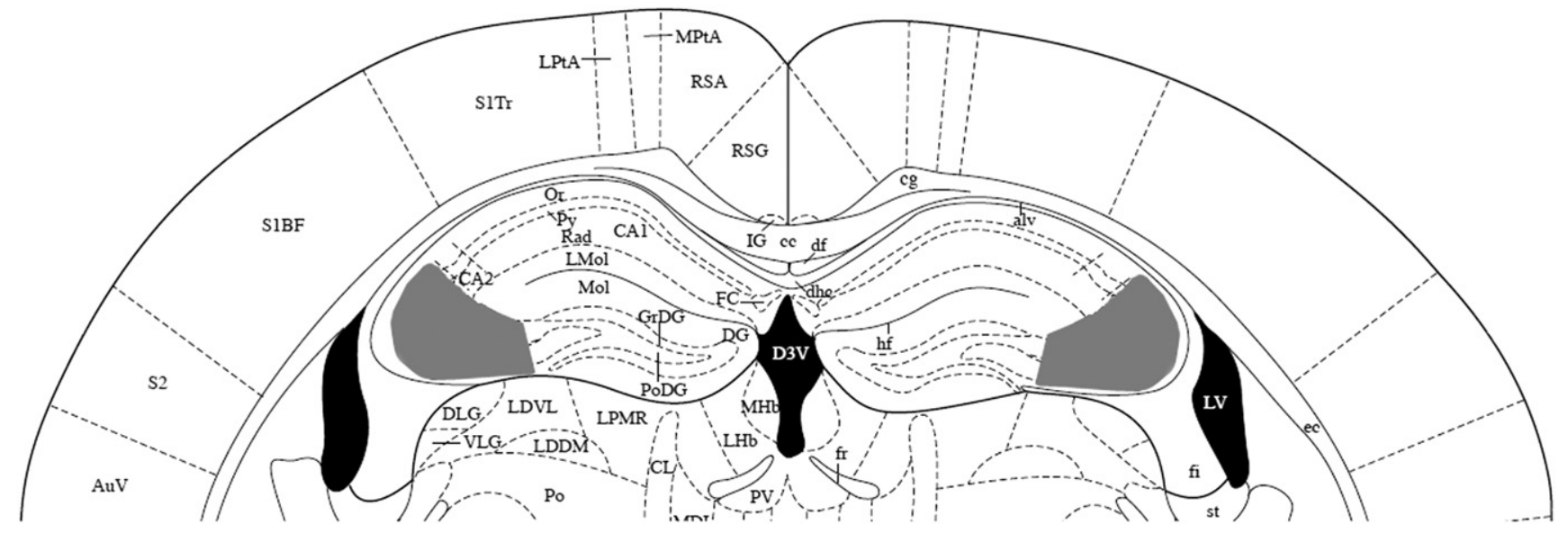

Figure 6. Schematic representation of the outer limits for acceptable injection sites in CA3 area of the dorsal hippocampus. Mice with injector tips falling outside the shaded area were excluded from the experiment.

CS-US pairing was repeated, then, $30 \mathrm{sec}$ after the second footshock, the mouse was gently removed from the chamber and underwent the injection process. After the infusion, the mouse was returned to its home cage. The second conditioning procedure consisted of two sessions with one learning trial each, spaced by a 2 -h interval (2-h IC). During each session the mouse stayed in the conditioning chamber for a total of $3 \mathrm{~min}$. After a 2-min exploration period, a sound was emitted for $30 \mathrm{sec}$ and coterminated with a 2-sec foot-shock. Thirty seconds later the mouse was removed from the conditioning chamber and underwent the injection process, and then was returned to its home cage. The same conditioning protocol was applied to the mouse $2 \mathrm{~h}$ after the first session, followed by a second injection. The last conditioning procedure consisted of two one-trial sessions spaced by a $24-h$ interval (24-h IC). This 24 -h IC procedure used the same conditions as those of the 2-h IC. Only the inter-session delay differed.

Whatever the training procedure, $24 \mathrm{~h}$ after the last conditioning session, freezing to the context was assessed by again placing each mouse in the conditioning chamber. The level of freezing was measured during $4 \mathrm{~min}$, no tone or foot-shock being presented to the animal. Two hours later, mice were tested for freezing to the tone in the modified context. Two minutes after introduction in the modified chamber, freezing was recorded during a 2-min tone presentation. Freezing is defined as the lack of movement besides breathing according to Blanchard and Blanchard (1969). This behavior was both automatically recorded and blind scored by an experimenter every $5 \mathrm{sec}$ during conditioning and recall test sessions. Data were converted to the percentage of samples scored at freezing and calculated for the 4-min context recall test, the 2-min pre-tone, and the 2-min tone tests.

\section{Intrahippocampal microinfusion procedure and drug diffusion}

Mice were infused immediately after each conditioning session. Prior to each infusion, the obturators were removed and an infusion cannula was inserted extending $1.1 \mathrm{~mm}$ beyond the end of the guide cannula. The infusion cannula was connected by a polypropylene tube to a Hamilton microsyringe that delivered the solution at the rate of $0.125 \mu \mathrm{L} / \mathrm{min}$, using an automated pump (Harvard Apparatus). A volume of $0.25 \mu \mathrm{L}$ was infused into each dorsal hippocampus, then injection cannulae were left in place for an additional $60 \mathrm{sec}$ to avoid capillary flow back and optimize diffusion of the solution. Possible spread of the injectant in adjacent areas was checked after the experiments using dye injections. The size of the bolus ensures that drugs do not spread out of the CA3 area (see Daumas et al. 2005 for further discussion).
Depending on the experimental conditions, mice could receive either one (2-min IC) or two injections over $1 \mathrm{~d}$ (2-h IC) or $2 \mathrm{~d}$ (24-h IC).

\section{Histological examination of cannulae tracks and infusion locations}

At the end of behavioral experiments, all mice were injected with thionin (under the same condition as the drugs) and then sacrificed by cervical dislocation before removing their brains. First, brains were stored for $24 \mathrm{~h}$ at room temperature in a solution of $2.5 \%$ glutaraldehyde $-30 \%$ sucrose $(1: 1)$ to fix the tissue, then they were placed for $24 \mathrm{~h}$ into sucrose (30\%) and stored in a refrigerator for dehydration. Afterward, brains were cut into $40-\mu \mathrm{m}$ coronal sections with a freezing microtome. To check that brains had been infused to the correct site, sections were mounted on gelatin-treated slides. The sections, only identified by noninformative numbers, were then examined with a light microscope to verify the adequate placement of guide cannulae and infusion sites. All mice that did not satisfy histological criteria were discarded from analyses.

After histological examination of brain slices, 53 mice of a total of 253 were taken out of the analysis because of unilateral infusion of the drug or misplacement of guide cannulae and/or injection. In all remaining mice, the tips of infusion cannulae were located in the area of interest (Fig. 6). This resulted in sample sizes ranging from six to 10 mice among the 18 experimental groups.

\section{Data analysis}

Mean freezing percentages for each group $( \pm$ SEM) are presented in the figures. Group sizes ranged from seven to 10 mice. To satisfy the requirements for the use of ANOVA, the mean percentages of freezing scores $(P)$ were transformed in $Q=\arcsin (\sqrt{ } P / 100)$. Statistical analyses were performed on the $Q$ variable, using oneway analysis of variance (ANOVA), or repeated measures ANOVA design for related samples (SYSTAT 11 for Windows). Prior to ANOVA, normality (Shapiro-Wilks test) and homoscedasticity (Bartlett test) were checked for every group. Post hoc comparisons were conducted using Fisher's LSD test. $\alpha$ levels were set at $P<0.05$.

\section{Acknowledgments}

This work was supported by CNRS and Université de Toulouse. We thank the ABC facility and ANEXPLO for housing mice. 


\section{References}

Abe K. 2001. Modulation of hippocampal long-term potentiation by the amygdala: a synaptic mechanism linking emotion and memory. Jpn J Pharmacol 86: 18-22.

Abe K, Niikura Y, Misawa M. 2003. The induction of long-term potentiation at amygdalo-hippocampal synapses in vivo. Biol Pharm Bull 26: 1560-1562.

Anagnostaras SG, Gale GD, Fanselow MS. 2001. Hippocampus and contextual fear conditioning: recent controversies and advances. Hippocampus 11: 8-17.

Bach ME, Hawkins RD, Osman M, Kandel ER, Mayford M. 1995. Impairment of spatial but not contextual memory in CaMKII mutant mice with a selective loss of hippocampal LTP in the range of the theta frequency. Cell 81: 905-915.

Besser L, Chorin E, Sekler I, Silverman WF, Atkin S, Russell JT, Hershfinkel M. 2009. Synaptically released zinc triggers metabotropic signaling via a zinc-sensing receptor in the hippocampus. J Neurosci 29: 2890-2901.

Blaabjerg M, Zimmer J. 2007. The dentate mossy fibers: structural organization, development and plasticity. Prog Brain Res 163: 85-107.

Blanchard RJ, Blanchard DC. 1969. Crouching as an index of fear. J Comp Physiol Psychol 67: 370-375.

Bliss TV, Collingridge GL. 1993. A synaptic model of memory: long-term potentiation in the hippocampus. Nature 361: 31-39.

Bortolotto ZA, Lauri S, Isaac JT, Collingridge GL. 2003. Kainate receptors and the induction of mossy fibre long-term potentiation. Philos Trans $R$ Soc Lond B Biol Sci 358: 657-666.

Bourtchouladze R, Abel T, Berman N, Gordon R, Lapidus K, Kandel ER. 1998. Different training procedures recruit either one or two critical periods for contextual memory consolidation, each of which requires protein synthesis and PKA. Learn Mem 5: 365-374.

Bourtchuladze R, Frenguelli B, Blendy J, Cioffi D, Schutz G, Silva AJ. 1994 Deficient long-term-memory in mice with a targeted mutation of the camp-responsive element-binding protein. Cell 79: 59-68.

Bovet D, Bovet-Nitti F, Oliverio A. 1969. Genetic aspects of learning and memory in mice. Science 163: 139-149.

Bramham CR, Milgram NW, Srebro B. 1991. Activation of AP5-sensitive NMDA receptors is not required to induce LTP of synaptic transmission in the lateral perforant path. Eur J Neurosci 3: 1300-1308.

Calandreau L, Trifilieff P, Mons N, Costes L, Marien M, Marighetto A, Micheau J, Jaffard R, Desmedt A. 2006. Extracellular hippocampal acetylcholine level controls amygdala function and promotes adaptive conditioned emotional response. J Neurosci 26: 13556-13566.

Ceccom J, Bouhsira E, Halley H, Daumas S, Lassalle JM. 2013. Differential needs of zinc in the CA3 area of dorsal hippocampus for the consolidation of contextual fear and spatial memories. Learn Mem 20: $348-351$.

Cerasti E, Treves A. 2010. How informative are spatial CA3 representations established by the dentate gyrus? PLoS Comput Biol 6: e1000759.

Cerasti E, Treves A. 2013. The spatial representations acquired in CA3 by self-organizing recurrent connections. Front Cell Neurosci 7: 112.

Cole TB, Wenzel HJ, Kafer KE, Schwartzkroin PA, Palmiter RD. 1999. Elimination of zinc from synaptic vesicles in the intact mouse brain by disruption of the ZnT3 gene. Proc Natl Acad Sci 96: 1716-1721.

Commins S, Cunningham L, Harvey D, Walsh D. 2003. Massed but not spaced training impairs spatial memory. Behav Brain Res 139: 215-223.

Daumas S, Halley H, Lassalle JM. 2004. Disruption of hippocampal CA3 network: effects on episodic-like memory processing in C57BL/6J mice. Eur J Neurosci 20: 597-600.

Daumas S, Halley H, Frances B, Lassalle JM. 2005. Encoding, consolidation and retrieval of contextual memory: differential involvement of CA3 and CA1 hippocampal subregions. Learn Mem 12: 375-382.

Daumas S, Betourne A, Halley H, Wolfer DP, Lipp HP, Lassalle JM, Frances B. 2007. Transient activation of the CA3 $\kappa$ opioid system in the dorsal hippocampus modulates complex memory processing in mice. Neurobiol Learn Mem 88: 94-103.

Daumas S, Ceccom J, Halley H, Frances B, Lassalle JM. 2009. Activation of metabotropic glutamate receptor type $2 / 3$ supports the involvement of the hippocampal mossy fiber pathway on contextual fear memory consolidation. Learn Mem 16: 504-507.

Diamond DM, Campbell AM, Park CR, Halonen J, Zoladz PR. 2007. The temporal dynamics model of emotional memory processing: a synthesis on the neurobiological basis of stress-induced amnesia, flashbulb and traumatic memories, and the Yerkes-Dodson law. Neural Plast 2007: 60803.

Fanselow MS, Kim JJ, Decola JP, Landeirafernandez J. 1990. Blockade of Pavlovian fear conditioning by the NMDA antagonist. Bull Psychon Soc 28: $527-528$.

Fellini L, Florian C, Courtey J, Roullet P. 2009. Pharmacological intervention of hippocampal CA3 NMDA receptors impairs acquisition and long-term memory retrieval of spatial pattern completion task. Learn Mem 16: 387-394.

Florian C, Roullet P. 2004. Hippocampal CA3-region is crucial for acquisition and memory consolidation in Morris water maze task in mice. Behav Brain Res 154: 365-374.

Frederickson R, Frederickson CJ, Danscher G. 1990. In situ binding of bouton zinc reversibly disrupts performance on a spatial memory task. Behav Brain Res 38: 25-33.

Gundelfinger ED, Boeckers TM, Baron MK, Bowie JU. 2006. A role for zinc in postsynaptic density asSAMbly and plasticity? Trends Biochem Sci 31: 366-373.

$\mathrm{Hu}$ H, Real E, Takamiya K, Kang MG, Ledoux J, Huganir RL, Malinow R. 2007. Emotion enhances learning via norepinephrine regulation of AMPA-receptor trafficking. Cell 131: 160-173.

Huang YY, Kandel ER. 1996. Modulation of both the early and the late phase of mossy fiber LTP by the activation of $\beta$-adrenergic receptors. Neuron 16: 611-617.

Huang YZ, Pan E, Xiong ZQ, McNamara JO. 2008. Zinc-mediated transactivation of TrkB potentiates the hippocampal mossy fiber-CA3 pyramid synapse. Neuron 57: 546-558.

Hubbard SR, Bishop WR, Kirschmeier P, George SJ, Cramer SP, Hendrickson WA. 1991. Identification and characterization of zinc binding sites in protein kinase C. Science 254: 1776-1779.

Ikegaya Y, Nakanishi K, Saito H, Abe K. 1997. Amygdala $\beta$-noradrenergic influence on hippocampal long-term potentiation in vivo. Neuroreport 8: $3143-3146$.

Ikegaya Y, Delcroix I, Iwakura Y, Matsuki N, Nishiyama N. 2003. Interleukin-1 $\beta$ abrogates long-term depression of hippocampal CA1 synaptic transmission. Synapse 47: 54-57.

Izumi Y, Auberson YP, Zorumski CF. 2006. Zinc modulates bidirectional hippocampal plasticity by effects on NMDA receptors. J Neurosci 26: 7181-7188.

Kerr AM, Jonas P. 2008. The two sides of hippocampal mossy fiber plasticity. Neuron 57: 5-7.

Kogan JH, Frankland PW, Blendy JA, Coblentz J, Marowitz Z, Schutz G, Silva AJ. 1997. Spaced training induces normal long-term memory in CREB mutant mice. Curr Biol 7: 1-11.

Koh J, Suh S, Gwag B, He Y, Hsu C, Choi D. 1996. The role of zinc in selective neuronal death after transient global cerebral ischemia. Science 272: 1013-1016.

Kuriyama K, Soshi T, Fujii T, Kim Y. 2010. Emotional memory persists longer than event memory. Learn Mem 17: 130-133.

Kwon HB, Castillo PE. 2008. Long-term potentiation selectively expressed by NMDA receptors at hippocampal mossy fiber synapses. Neuron 57: $108-120$.

Lassalle JM, Bataille T, Halley H. 2000. Reversible inactivation of the hippocampal mossy fiber synapses in mice impairs spatial learning, but neither consolidation nor memory retrieval, in the Morris navigation task. Neurobiol Learn Mem 73: 243-257.

Lee JC, Hynds RE. 2013. Divergent cellular pathways of hippocampal memory consolidation and reconsolidation. Hippocampus 23: $233-244$.

Lee JLC, Everitt BJ, Thomas KL. 2004. Independent cellular processes for hippocampal memory consolidation and reconsolidation. Science 304: 839-843.

Lehmann H, McNamara KC. 2011. Repeatedly reactivated memories become more resistant to hippocampal damage. Learn Mem 18: $132-135$.

Lengyel I, Fieuw-Makaroff S, Hall AL, Sim ATR, Rostas JAP, Dunkley PR. 2000. Modulation of the phosphorylation and activity of calcium/ calmodulin-dependent protein kinase II by zinc. J Neurochem 75: 594-605.

Li Y, Hough CJ, Frederickson CJ, Sarvey JM. 2001a. Induction of mossy fiber $\rightarrow$ CA3 long-term potentiation requires translocation of synaptically released $\mathrm{Zn}^{2+}$. J Neurosci 21: 8015-8025.

Li Y, Hough CJ, Suh SW, Sarvey JM, Frederickson CJ. 2001b. Rapid translocation of $\mathrm{Zn}^{2+}$ from presynaptic terminals into postsynaptic hippocampal neurons after physiological stimulation. J Neurophysiol 86: $2597-2604$

Li YV, Hough CJ, Sarvey JM. 2003. Do we need zinc to think? Science stke. 182: pe19. doi: 10.1126/stke.2003.182.pe19.

Linkous DH, Flinn JM, Koh JY, Lanzirotti A, Bertsch PM, Jones BF, Giblin LJ, Frederickson CJ. 2008. Evidence that the ZnT3 protein controls the total amount of elemental zinc in synaptic vesicles. J Histochem Cytochem 56: 3-6.

Lisman JE. 1999. Relating hippocampal circuitry to function: recall of memory sequences by reciprocal dentate-CA3 interactions. Neuron 22: 233-242.

Lu Y-M, Taverna FA, Tu R, Ackerley CA, Wang Y-T, Roder J. 2000. Endogenous $\mathrm{Zn}^{2+}$ is required for the induction of long-term potentiation at rat hippocampal mossy fiber-CA3 synapses. Synapse 38: $187-197$. 
Malherbe P, Richards JG, Broger C, Zenner MT, Messer J, Kratzeisen C, Nakanishi S, Mutel V. 2005. Opposite effects of $\mathrm{Zn}$ on the in vitro binding of $\left[{ }^{3} \mathrm{H}\right] \mathrm{LY} 354740$ to recombinant and native metabotropic glutamate 2 and 3 receptors. J Neurochem 94: 150-160.

Manzerra P, Behrens MM, Canzoniero LMT, Wang XQ, Heidinger V, Ichinose T, Yu SP, Choi DW. 2001. Zinc induces a Src family kinase-mediated up-regulation of NMDA receptor activity and excitotoxicity. Proc Natl Acad Sci 98: 11055-11061.

Marr D. 1971. Simple memory: a theory for archicortex. Philos Trans R Soc Lond B Biol Sci 262: 23-81.

Martel G, Hevi C, Friebely O, Baybutt T, Shumyatsky GP. 2010. Zinc transporter 3 is involved in learned fear and extinction, but not in innate fear. Learn Mem 17: 582-590.

McNaughton N, Morris RG. 1987. Chlordiazepoxide, an anxiolytic benzodiazepine, impairs place navigation in rats. Behav Brain Res 24: $39-46$.

Nakao K, Matsuyama K, Matsuki N, Ikegaya Y. 2004. Amygdala stimulation modulates hippocampal synaptic plasticity. Proc Natl Acad Sci 101: $14270-14275$.

Nakazawa K, Sun LD, Quirk MC, Rondi-Reig L, Wilson MA, Tonegawa S. 2003. Hippocampal CA3 NMDA receptors are crucial for memory acquisition of one-time experience. Neuron 38: 305-315.

Nicoll RA, Schmitz D. 2005. Synaptic plasticity at hippocampal mossy fibre synapses. Nat Rev Neurosci 6: 863-876.

O'Keefe J, Dostrovsky J. 1971. The hippocampus as a spatial map. Preliminary evidence from unit activity in the freely-moving rat. Brain Res 34: $171-175$

Overduin SA, Richardson AG, Lane CE, Bizzi E, Press DZ. 2006. Intermittent practice facilitates stable motor memories. J Neurosci 26: 11888-11892.

Park JA, Koh JY. 1999. Induction of an immediate early gene egr-1 by zinc through extracellular signal-regulated kinase activation in cortical culture: Its role in zinc-induced neuronal death. J Neurochem 73: $450-456$.

Paxinos G, Franklin KBJ. 2001. The mouse brain in stereotaxic coordinates. Academic Press, San Diego, CA.

Phillips RG, Ledoux JE. 1992. Differential contribution of amygdala and hippocampus to cued and contextual fear conditioning. Behav Neurosci 106: $274-285$.

Pinheiro PS, Mulle C. 2008. Presynaptic glutamate receptors: physiological functions and mechanisms of action. Nat Rev Neurosci 9: 423-436.

Rebola N, Lujan R, Cunha RA, Mulle C. 2008. Adenosine A2A receptors are essential for long-term potentiation of NMDA-EPSCs at hippocampal mossy fiber synapses. Neuron 57: 121-134.

Rolls ET. 2007. An attractor network in the hippocampus: theory and neurophysiology. Learn Mem 14: 714-731.

Scharf MT, Woo NH, Lattal KM, Young JZ, Nguyen PV, Abel T. 2002. Protein synthesis is required for the enhancement of long-term potentiation and long-term memory by spaced training. J Neurophysiol 87: $2770-2777$

Schildt S, Endres T, Lessmann V, Edelmann E. 2013. Acute and chronic interference with BDNF/TrkB-signaling impair LTP selectively at mossy fiber synapses in the CA3 region of mouse hippocampus. Neuropharmacol 71: 247-254.

Schmitz D, Mellor J, Nicoll RA. 2001. Presynaptic kainate receptor mediation of frequency facilitation at hippocampal mossy fiber synapses. Science 291: 1972-1976.

Sensi SL, Paoletti P, Bush AI, Sekler I. 2009. Zinc in the physiology and pathology of the CNS. Nat Rev Neurosci 10: 780-792.

Sensi SL, Paoletti P, Koh JY, Aizenman E, Bush AI, Hershfinkel M. 2011. The neurophysiology and pathology of brain zinc. J Neurosci 31: $16076-16085$.

Shigemoto R, Kinoshita A, Wada E, Nomura S, Ohishi H, Takada M, Flor PJ, Neki A, Abe T, Nakanishi S, et al. 1997. Differential presynaptic localization of metabotropic glutamate receptor subtypes in the rat hippocampus. J Neurosci 17: 7503-7522.

Sigurdsson T, Doyere V, Cain CK, LeDoux JE. 2007. Long-term potentiation in the amygdala: a cellular mechanism of fear learning and memory. Neuropharmacol 52: 215-227.

Sindreu CB, Varoqui H, Erickson JD, Perez-Clausell J. 2003. Boutons containing vesicular zinc define a subpopulation of synapses with low AMPAR content in rat hippocampus. Cereb Cortex 13: 823-829.

Sindreu C, Palmiter RD, Storm DR. 2011. Zinc transporter ZnT-3 regulates presynaptic Erk1/2 signaling and hippocampus-dependent memory. Proc Natl Acad Sci 108: 3366-3370.

Smart TG, Hosie AM, Miller PS. 2004. $\mathrm{Zn}^{2+}$ ions: modulators of excitatory and inhibitory synaptic activity. Neuroscientist 10: 432-442.

Stupien G, Florian C, Roullet P. 2003. Involvement of the hippocampal CA3-region in acquisition and in memory consolidation of spatial but not in object information in mice. Neurobiol Learn Mem 80: 32-41.

Sudhof TC. 1995. The synaptic vesicle cycle: a cascade of protein-protein interactions. Nature 375: 645-653.

Takeda A, Sawashita J, Takefuta S, Ohnuma M, Okada S. 1999. Role of zinc released by stimulation in rat amygdala. J Neurosci Res 57: 405-410.

Takeda A, Minami A, Seki Y, Oku N. 2004. Differential effects of zinc on glutamatergic and GABAergic neurotransmitter systems in the hippocampus. J Neurosci Res 75: 225-229.

Takeda A, Nakajima S, Fuke S, Sakurada N, Minami A, Oku N. 2006. Zinc release from Schaffer collaterals and its significance. Brain Res Bull 68: $442-447$.

Takeda A, Fuke S, Minami A, Oku N. 2007. Role of zinc influx via AMPA/ kainate receptor activation in metabotropic glutamate receptor-mediated calcium release. J Neurosci Res 85: 1310-1317.

Takeda A, Fuke S, Ando M, Oku N. 2008a. Positive modulation of long-term potentiation at hippocampal CA1 synapses by low micromolar concentrations of zinc. Neurosci 158: 585-591.

Takeda A, Kanno S, Sakurada N, Ando M, Oku N. 2008b. Attenuation of hippocampal mossy fiber long-term potentiation by low micromolar concentrations of zinc. J Neurosci Res 86: 2906-2911.

Takeda A, Sakurada N, Ando M, Kanno S, Oku N. 2009. Facilitation of zinc influx via AMPA/kainate receptor activation in the hippocampus. Neurochem Int 55: 376-382.

Takeda A, Iwaki H, Ando M, Itagaki K, Suzuki M, Oku N. 2010. Zinc differentially acts on components of long-term potentiation at hippocampal CA1 synapses. Brain Res 1323: 59-64.

Treves A, Rolls ET. 1992. Computational constraints suggest the need for two distinct input systems to the hippocampal CA3 network. Hippocampus 2: 189-199.

Tully K, Bolshakov VY. 2010. Emotional enhancement of memory: how norepinephrine enables synaptic plasticity. Mol Brain 3: 15. doi: 10.1186/1756-6606-3-15.

Ueno S, Tsukamoto M, Hirano T, Kikuchi K, Yamada MK, Nishiyama N, Nagano T, Matsuki N, Ikegaya Y. 2002. Mossy fiber $\mathrm{Zn}^{2+}$ spillover modulates heterosynaptic $\mathrm{N}$-methyl-D-aspartate receptor activity in hippocampal CA3 circuits. J Cell Biol 158: 215-220.

Vogt K, Mellor J, Tong G, Nicoll R. 2000. The actions of synaptically released zinc at hippocampal mossy fiber synapses. Neuron 26: 187-196.

Wiltgen BJ, Zhou M, Cai Y, Balaji J, Karlsson MG, Parivash SN, Li WD, Silvaz AJ. 2010. The hippocampus plays a selective role in the retrieval of detailed contextual memories. Curr Biol 20: 1336-1344.

Yeckel MF, Kapur A, Johnston D. 1999. Multiple forms of LTP in hippocampal CA3 neurons use a common postsynaptic mechanism. Nat Neurosci 2: 625-633.

Received October 3, 2013; accepted in revised form January 31, 2014. 


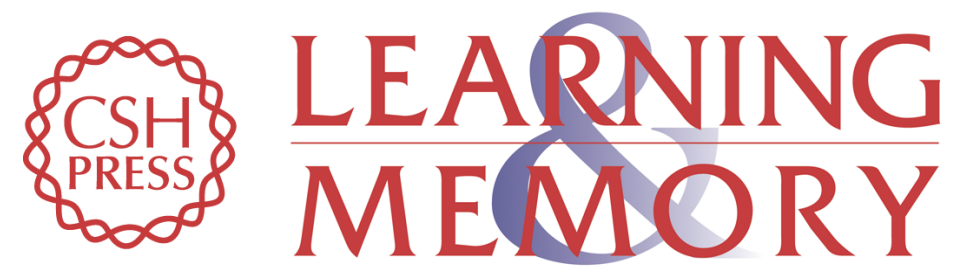

\section{A specific role for hippocampal mossy fiber's zinc in rapid storage of emotional memories}

Johnatan Ceccom, Hélène Halley, Stéphanie Daumas, et al.

Learn. Mem. 2014, 21:

Access the most recent version at doi:10.1101/Im.033472.113

\begin{tabular}{cl}
\hline References & $\begin{array}{l}\text { This article cites } 93 \text { articles, } 26 \text { of which can be accessed free at: } \\
\text { http://learnmem.cshlp.org/content/21/5/287.full.html\#ref-list-1 }\end{array}$ \\
$\begin{array}{c}\text { Creative } \\
\text { Commons } \\
\text { License }\end{array}$ & $\begin{array}{l}\text { This article is distributed exclusively by Cold Spring Harbor Laboratory Press for the } \\
\text { first } 12 \text { months after the full-issue publication date (see } \\
\text { http://learnmem.cshlp.org/site/misc/terms.xhtml). After } 12 \text { months, it is available under } \\
\text { a Creative Commons License (Attribution-NonCommercial } 4.0 \text { International), as } \\
\text { described at http://creativecommons.org/licenses/by-nc/4.0/. }\end{array}$ \\
$\begin{array}{c}\text { Receive free email alerts when new articles cite this article - sign up in the box at the } \\
\text { Service }\end{array}$ & $\begin{array}{l}\text { Rep right corner of the article or click here. } \\
\text { terting }\end{array}$ \\
\hline
\end{tabular} 